\title{
Immunoglobulin G Levels in the Gingival Crevicular Fluid of Menopausal Patients with Periodontitis
}

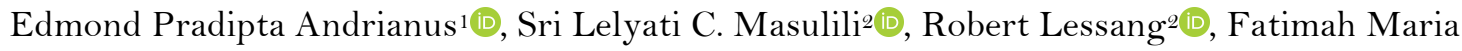

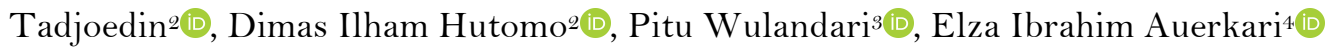

\footnotetext{
${ }^{1}$ Periodontics Residency Program, Faculty of Dentistry, Universitas Indonesia, Jakarta, Indonesia. ${ }^{2}$ Department of Periodontics, Faculty of Dentistry, Universitas Indonesia, Jakarta, Indonesia.

${ }^{3}$ Doctoral Program, Faculty of Dentistry, Universitas Indonesia, Jakarta, Indonesia.

${ }^{4}$ Department of Oral Biology, Faculty of Dentistry, Universitas Indonesia, Jakarta, Indonesia.
}

Correspondence: Sri Lelyati C. Masulili, Department of Periodontics, Faculty of Dentistry, Universitas Indonesia, Jakarta, Indonesia. E-mail: srilelyati@yahoo.com

Academic Editor: Alessandro Leite Cavalcanti

Received: 18 March 2020 / Review: 27 September 2020 / Accepted: 19 December 2020

\begin{abstract}
How to cite: Andrianus EP, Masulili SLC, Lessang R, Tadjoedin FM, Hutomo DI, Wulandari P, et al. Immunoglobulin G levels in the gingival crevicular fluid of menopausal patients with periodontitis. Pesqui Bras Odontopediatria Clín Integr. 2021; $21:$ :5940. https://doi.org/10.1590/pboci.2021.080
\end{abstract}

\begin{abstract}
Objective: To measure the level of immunoglobulin $\mathrm{G}(\mathrm{IgG})$ in the gingival crevicular fluid (GCF). Material and Methods: A total of 158 patients aged $>45$ years were examined for periodontitis and interviewed regarding their menopausal status. The non-menopause group entailed female patients with periodontitis without menopause $(\mathrm{n}=23)$. The menopause group included females who stopped menstruating since $>1$ year, had a pocket depth of 4-5 mm, and did not have other systemic conditions $(n=40)$. Samples were selected based on periodontal and menopausal status. In total, 63 samples of GCF were collected from the participants and tested using an enzyme-linked immunosorbent assay kit for IgG. Results: The median level of IgG in the menopause group was $39.50 \mathrm{mg} / \mathrm{mL}$, whereas that of the nonmenopause group was $41.08 \mathrm{mg} / \mathrm{mL}$. There was a positive correlation between the plaque index and $\operatorname{IgG}$ level in both groups. In contrast, there was a negative correlation between age and IgG level. However, there was no correlation between plaque index and age regarding the IgG level in both groups ( $\mathrm{p}>0.05)$. Conclusion: The IgG levels in the menopause group were lower than those in the non-menopause group. As such, menopausal females should take great care of their overall health, including the periodontium.
\end{abstract}

Keywords: Immunoglobulin G; Periodontal Diseases; Periodontitis; Menopause. 


\section{Introduction}

Periodontitis is one of the most prevalent diseases in Indonesia. It has multifactorial causes and can be exaggerated by systemic conditions, such as hormonal changes in females [1]. Menopause is a physiological condition in females that is diagnosed by permanent cessation of the menstrual cycle for $>1$ year. This usually occurs at the age of $\geq 45$ years [2-4]. According to the World Health Organization, the number of females aged $>60$ years dominates the total female population, with 336 million in 2000. This is expected to surpass one billion in 2050. Menopausal females experience hormonal imbalances, such as estrogen and progesterone imbalances, which affect their oral health [5-7]. This leads to a compromised immune system and inhibits polymorphonuclear cell chemotaxis and phagocytosis. Consequently, the oral mucosal is more susceptible to infection $[1,8-10]$.

Immunoglobulin $G(\operatorname{IgG})$ is part of the immune system that protects the periodontal tissue from pathogens and can be found in the gingival crevicular fluid (GCF). Decreasing immunoglobulin levels, especially $\operatorname{IgG}$, will increase periodontal disease progression [11-13]. Estrogen regulates the glycosylation of $\mathrm{IgG}$, which is necessary for $\mathrm{IgG}$ to function as an anti-inflammatory agent. Decreasing estrogen levels results in suppression of the anti-inflammatory effect of $\mathrm{IgG}$, thereby increasing the risk of progression of periodontal disease [14]. IgG is activated in chronic inflammatory processes such as in periodontitis. This antibody works through several mechanisms, including binding pathogens and causing their immobilization, binding and neutralizing toxins, as well as coating pathogens for the body to recognize and eliminate them through phagocytosis [15-18]. This research was conducted to assess the level of IgG in the GCF of menopausal patients with periodontitis to identify the effect of menopause on periodontitis in elderly female patients.

\section{Material and Methods}

\section{Study Design}

This is a cross-sectional study and was conducted at the Elderly Social Institution in Jakarta Selatan, Indonesia.

\section{Sample and Data Collection}

The population comprised elderly females living in the nursing home. A total of 158 patients aged $>45$ years were examined for periodontitis and interviewed regarding their menopausal status. The periodontal status of patients who completed the interview was subsequently examined by measuring the pocket depth, gingival recession, and oral hygiene index, including the probe bleeding index, plaque index, and calculus index using a UNC 15 periodontal probe (Osung Dental Instruments, TX, USA). Tooth mobility was also assessed.

The inclusion criteria were females who achieved menopause since $>1$ year, periodontitis with a gingival pocket depth of 4-5 mm, and patients who did not have other systemic conditions besides menopause; these patients were included in the menopause group $(\mathrm{MG}=40)$. Females aged 18-45 years with periodontitis without menopause who did not have any systemic diseases and had a gingival pocket depth of 4-5 mm were included in the non-menopause group $(\mathrm{NMG}=23)$.

Samples were collected from gingival pockets using a paper point number 20 that was inserted into the pocket for 30 s. Paper point \#20 (Gadapen, Tianjin, China) was stored in an Eppendorf tube with phosphate buffer saline solution to preserve it. Samples were analyzed using an enzyme-linked immunosorbent assay kit (Elabscience Inc., Houston, TX, USA) at Indonesian Medical Education and Research, Indonesia. 


\section{Data Analysis}

The clinical data were analyzed using IBM SPSS, version 21.0 (IBM Corp., Armonk, NY, USA). The Mann-Whitney $\mathrm{U}$ test and independent T-test were used. Spearman analysis was used as the correlation test. The clinical parameter of both groups was $\mathrm{p}<0.05$, which was considered significant.

Ethical Clearance

This study was approved by the Ethical Committee of Faculty of Dentistry, Universitas Indonesia, Protocol No. 090400419, and all patients signed and informed consent.

\section{Results}

For the menopause group, the mean plaque index was 1.83 , clinical attachment loss was 4.5 and $\operatorname{IgG}$ level was 38.18 (Table 1).

Table 1. Data distribution based on clinical and laboratory parameters.

\begin{tabular}{llccc}
\hline \multicolumn{1}{c}{ Clinical and Laboratory Parameters } & \multicolumn{1}{c}{ Groups } & Mean & Median (Min.-Max.) & p-value \\
\hline Age (Years) & Menopause & 69.25 & $70(67-75)$ & 0.002 \\
& Non-menopause & 38.50 & $38(36-45)$ & 0.021 \\
Plaque Index & Menopause & 1.83 & $1.70(0.23-3.00)$ & $0.287^{*}$ \\
& Non-menopause & 0.88 & $0.71(0.38-1.75)$ & $0.144^{*}$ \\
Clinical Attachment Loss $(\mathrm{mm})$ & Menopause & 4.5 & $4.52(2.35-8.50)$ & 0.012 \\
& Non-menopause & 0.30 & $0.13(0.04-0.90)$ & 0.006 \\
IgG Level (ng/mL) & Menopause & 38.18 & $39.50(5.84-66.11)$ & $0.264^{*}$ \\
& Non-menopause & 47.34 & $41.08(25.56-99.49)$ & 0.006 \\
\hline
\end{tabular}

Saphiro-Wilk test; *p-value- $\geq 0.05$ normal data.

The distribution for clinical and laboratory parameters within menopause status was normal in plaque index group.

According to Table 2, there was no statistically significant difference in the IgG level; however, the median IgG level in the non-menopause group was higher than that in the menopause group.

Table 2. The immunoglobulin-G level on menopause and non-menopause groups.

\begin{tabular}{lcc}
\hline \multicolumn{1}{c}{ Groups } & $\begin{array}{c}\text { Immunoglobulin-G Level (ng/mL) } \\
\text { Median (Min.-Max.) }\end{array}$ & p-value* \\
\hline Menopause & $39.50(5.84-66.11)$ & 0.206 \\
Non-menopause & $41.08(25.56-99.49)$ & \\
\hline *Independent T-test. & &
\end{tabular}

\section{Discussion}

$\operatorname{IgG}$ is one of the main humoral immune responses regarding preventing periodontal disease. In women, the immune system can be affected by hormonal changes in puberty, pregnancy, and menopause. Menopause is the term for the female condition in which the menstrual cycle has permanently ceased for at least one year. This alters the progesterone and estrogen levels. A decrease in progesterone and estrogen levels deteriorates the immune system function. The present study shows that menopausal women are at an increased risk of developing periodontal disease than women who are not in menopause $[7,19]$.

In menopausal females, the gingiva becomes more susceptible to inflammation and the periodontium is susceptible to bone loss as the estrogen levels decrease. Estrogen deficiency causes the release of proinflammatory cytokines and causes a higher risk of bone-resorption in periodontitis. Plaque accumulation is the 
main cause of periodontal disease initiation, and an inadequate amount of estrogen results in decreased salivary flow. Saliva generally functions as an oral cleansing agent, and a decline in its flow results in increased plaque build-up compared with the non-menopausal female [14].

Progesterone influences the immune system and thereby the periodontium in many ways, including inhibiting pro-inflammatory cytokines, suppressing leukocyte production, inhibiting polymorphonuclear neutrophils $(\mathrm{PMN})$, and stimulating PMN phagocytosis; however, there is no information on its effect on immunoglobulin, particularly IgG [20]. IgG works by binding pathogens, such as viruses and bacteria. In this case, it binds and eliminates periodontal pathogens. As the humoral immune response in chronic disease, including periodontitis, IgG can be found in the GCF of patients with periodontitis.

Cross-sectional data for this study was obtained from 63 samples. This study shows that the median IgG level in the menopause group was lower than that in the non-menopause group. Although the median score was higher in the menopause group, statistical analysis shows no significant difference. The Spearman correlation test also showed no significant correlation between age or plaque index and the IgG level; however, there is a positive correlation between the plaque index and the $\operatorname{IgG}$ level, and a negative correlation between age and $\operatorname{IgG}$ level. A positive correlation means that as the plaque index increase, the IgG level also increases. In contrast, a negative correlation means that as age increases, the $\operatorname{IgG}$ levels decrease.

Several confounding factors in the sampling process were not excluded, such as plaque index, clinical attachment loss, and age limitation for both groups. These can affect the results. Periodontitis severity, which was showed by clinical attachment loss and plaque index, may also interfere with the IgG level as it is higher in patients with more pathogens. A higher plaque index indicates more bacteria, and as such, the IgG level will increase. The age limitation related to the immune system in a person decreases as the person gets older. The IgG levels also decrease. The IgG levels are lower in older people than in younger people with the same disease level because of the degradation of cell function. Those were the weaknesses of this study. The samples have a varying range of severity of periodontitis, which can affect the IgG level as IgG was not only influenced by local but also the entire state of the mouth.

The immune system is not only influenced by menopause but also by a multitude of factors. Other conditions, such as degenerative cells on aging and chronic systemic infections or diseases, can also affect IgG level in GCF.

\section{Conclusion}

There was no significant effect of menopause on the IgG level in periodontal disease, specifically periodontitis. There was also no correlation between plaque index or age and the level of IgG. Many factors can affect a woman's immune system, including IgG level, which declines during menopause. Further studies should enhance the inclusive criteria and be more specific.

\section{Authors' Contributions}

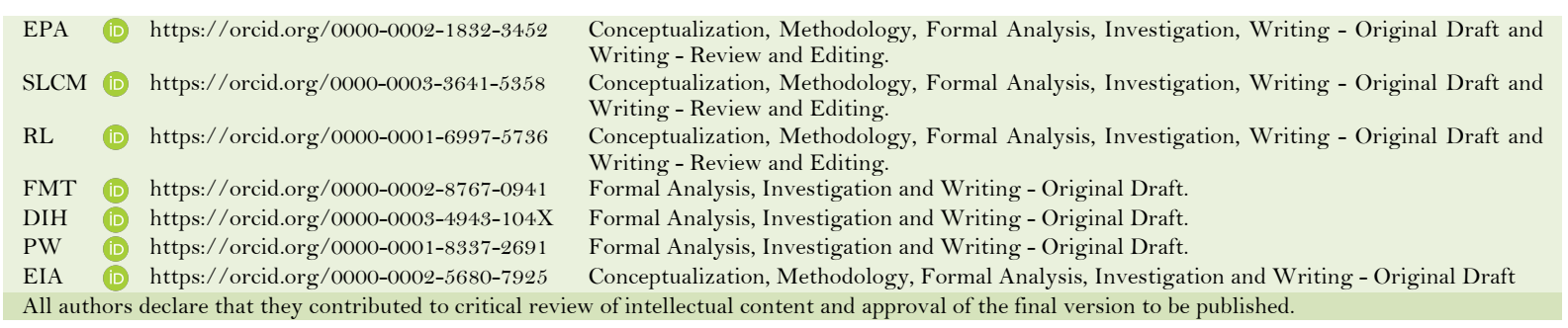




\section{Financial Support}

This study was supported by PITTA B UI 2019 Grant NKB-0581/UN2.R3.1/HKPo5.00/2019.

\section{Conflict of Interest}

The authors declare no conflicts of interest.

\section{Data Availability}

The data used to support the findings of this study can be made available upon request to the corresponding author.

\section{References}

[1] Haas AN, Rösing CK, Oppermann RV, Albandar JM, Susin C. Association among menopause, hormone replacement therapy, and periodontal attachment loss in Southern Brazilian women. J Periodontol 2009; 80(9):1380-7. https://doi.org/10.1902/jop.2009.090082

[2] Gomes-Filho IS, Oliveira TJS, Passos JS, Cerqueira EMM, Cruz SS, Barreto ML, et al. Effect of osteoporosis on periodontal therapy among post-menopausal women. Gerodontology 2013; 30(1):40-8. https://doi.org/10.1111/j.1741-2358.2012.00643.x

[3] Pavičin IS, Dumančić J, Jukić T, Badel T. The relationship between periodontal disease, tooth loss and decreased skeletal bone mineral density in ageing women. Gerodontology 2017; 34(4):441-5. https://doi.org/10.1111/ger.12290

[4] Shi T, Min M, Sun C, Zhang Y, Liang M, Sun Y. Periodontal disease and susceptibility to breast cancer: A metaanalysis of observational studies. J Clin Periodontol 2018; 45(9):1025-33. https://doi.org/10.1111/jcpe.12982

[5] Mai X, Genco RJ, LaMonte MJ, Hovey KM, Freudenheim JL, Andrews CA, et al. Periodontal pathogens and risk of incident cancer in postmenopausal females: The Buffalo OsteoPerio Study. J Periodontol 2016; 87(3):257-67. https://doi.org/10.1902/jop.2015.150433

[6] Taichman LS, Inglehart MR, Giannobile WV, Braun T, Kolenic G, Van Poznak CV. Periodontal health in women with early-stage postmenopausal breast cancer newly on aromatase inhibitors: a pilot study. J Periodontol 2015; 86(7):906-16. https://doi.org/10.1902/jop.2015.140546

[7] Varghese T, Madhumala R, Ravi RS, Varghese A. Evaluation of periodontal status among premenopausal and postmenopausal women- a comparative study. Ann Int Med Dent Res 2016; 2(6):46-9. https://doi.org/10.2 1276/aimdr.2016.2.6.de10

[8] Yoshida N, Sugimoto K, Suzuki S, Kudo H. Change in oral health status associated with menopause in Japanese dental hygienists. Int J Dent Hyg 2018; 16(1):157-64. https://doi.org/10.1111/idh.12282

[9] Khosravisamani M, Maliji G, Seyfi S, Azadmehr A, Nikfarjam BA, Madadi S, et al. Effect of the menstrual cycle on inflammatory cytokines in the periodontium. J Periodontal Res 2014; 49(6):770-6. https://doi.org/10.1111/jre.12161

[10] Chandra RV, Sailaja S, Reddy AA. Estimation of tissue and crevicular fluid oxidative stress marker in premenopausal, perimenopausal and postmenopausal women with chronic periodontitis. Gerodontology 2017; 34(3):382-9. https://doi.org/10.1111/ger. 12279

[11] Scardina GA, Messina P. Oral microcirculation in post-menopause: A possible correlation with periodontitis. Gerodontology 2012; 29(2):1045-51. https://doi.org/10.1111/j.1741-2358.2011.00608.x

[12] Huynh AHS, Veith PD, McGregor NR, Adams GG, Chen D, Reynolds EC, et al. Gingival crevicular fluid proteomes in health, gingivitis and chronic periodontitis. J Periodontal Res. 2015; 50(5):637-49. https://doi.org/10.1111/jre.12244

[13] Marshall JS, Warrington R, Watson W, Kim HL. An introduction to immunology and immunopathology. Allergy Asthma Clin Immunol 2018; 14(Suppl 2):49. https://doi.org/10.1186/s13223-018-0278-1

[14] Engdahl C, Bondt A, Harre U, Raufer J, Pfeifle R, Camponeschi A, et al. Estrogen induces St6gal 1 expression and increases IgG sialylation in mice and patients with rheumatoid arthritis : a potential explanation for the increased risk of rheumatoid arthritis in postmenopausal women. Arthritis Res Ther 2018; 20(1):84. https://doi.org/10.1186/s13075-018-1586-z

[15] Alves RC, Félix SA, Rodriguez-Archilla A, Oliveira P, Brito J, Santos JM. Relationship between menopause and periodontal disease: a cross-sectional study in a Portuguese population. Int J Clin Exp Med 2015; 8(7):11412-9.

[16] Choi Y, McKeown RE, Mayer-Davis EJ, Liese AD, Song K, Merchant AT. Serum C-reactive protein and immunoglobulin $\mathrm{g}$ antibodies to periodontal pathogens may be effect modifiers of periodontitis and hyperglycemia. $\mathrm{J}$ Periodontol. 2014; 85(9):1172-81. https://doi.org/10.1902/jop.2014.130658

[17] Yilmazer M, Fenkci V, Fenkci S, Aktepe O, Sonmezer M, Kurtay G. Association of serum complement (C3, C4) and immunoglobulin (IgG, $\operatorname{IgM}$ ) levels with hormone replacement therapy in healthy post-menopausal women. Hum Reprod. 2003; 18(7):1531-5. https://doi.org/10.1093/humrep/deg292 
[18] Costalonga M, Herzberg MC. The oral microbiome and the immunobiology of periodontal disease and caries. Immunol Lett 2014; 162(2 Pt A):22-38. https://doi.org/10.1016/j.imlet.2014.08.017

[19] Khan D, Ahmed SA. The immune system is a natural target for estrogen action: Opposing effects of estrogen in two prototypical autoimmune diseases. Front Immunol. 2016; 6:635. https://doi.org/10.3389/fimmu.2015.00635

[20] Wulandari P, Masulili SLC, Tadjoedin FM, Kemal Y, Kusdhany LS. The relationship between estrogen levels and periodontal status in postmenopausal women. J Int Dent Med Res 2017;10(September Issue):657-62. 